\title{
Posterior Segment Changes Following Uncomplicated Cataract Surgery-A Study with B-Scan and OCT
}

\author{
Authors \\ Jayasree P Venugopal ${ }^{1}$, Mallika O $\mathbf{U}^{2}$, Rajini K $\mathrm{C}^{1}$ \\ Government Medical College Thrissur \\ Corresponding Author \\ Jayasree $P$ Venugopal \\ No.83,'Souhruda', Chaitanyapuram, D.K. Halli Road, BEML Nagar, \\ KGF (Kolar), Karnataka, PIN 563115 \\ Email: venugopaljayasree@yahoo.co.in, +919739094954
}

\begin{abstract}
Purpose: To assess the posterior segment changes following uncomplicated cataract surgery-SICS using ultrasound B-scan and optical coherence tomography.

Materials and Methods: In a prospective study, 50 patients who underwent an uncomplicated small incision cataract surgery were analysed with ultrasonography (USG) and optical coherence tomography (OCT) preoperatively, and post operatively at 1 week, 1 month, and 3 months. Mean, standard deviation and Chisquare test were the statistical methods used.

Results: The mean age of subjects were 65.50 +/- 10.2 years, $62 \%(31)$ were female (62\%) and 38\% (19) were male. Preoperatively, 46 patients (92\%) had normal USG, 4 (8\%) had incomplete posterior vitreous detachment (PVD) and the central foveal thickness was found to be 147.80+/- 17.182 micro meters. Postoperatively, incidence of PVD at 3 months was 34\%. PVD was noted more in those above 65 years of age than those below (50.0\% vs 16.7\%, p<0.05). 3 patients (6\%) had macular edema, of which 1 (2\%) had cystoid macular edema. The event of having macular edema was more likely in diabetic (22.2\%) than non-diabetic patients $(2.4 \%)$. The $p$ value $<0.05$ by chi square test; indicates that there was a statistically significant correlation between presence of macular edema and reduction in visual acuity.

Conclusions: Ultrasonography and optical coherence tomography are non-invasive and efficient tools for assessment of posterior segment of the eye. Ultra sound B-scan effectively detects posterior vitreous detachment. Incidence of pseudophakic posterior vitreous detachment increase with age. Optical coherence tomography aids in the early detection, diagnosis and follow up of cystoid macular edema. Diabetes mellitus appears to predispose a patient to post-operative macular edema and cystoid macular edema seems to be an important cause of reduced visual acuity after uncomplicated cataract surgery.
\end{abstract}

Keywords: SICS, central foveal thickness, macular edema, posterior vitreous detachment.

\section{Introduction}

According to WHO; "Cataract is clouding of the lens of the eye which impedes the passage of
light."Globally, cataract is the single most important cause of blindness and cataract surgery has been shown to be one of the most cost-effective health- 
care interventions resulting in almost immediate visual rehabilitation. ${ }^{1}$

Normal posterior segment of the eye is an important prerequisite for good visual outcome after cataract surgery. Ultrasonography of the eye is a noninvasive method of assessing posterior segment of the eye; it is especially important in case of cataract where the view to posterior segment is otherwise hindered. ${ }^{2}$ It detects posterior segment pathologies like posterior vitreous detachment, retinal detachment, vitreous hemorrhage, vitritis, mass lesions of retina and choroid.

Even an uncomplicated cataract surgery can result in certain complications like posterior vitreous detachment, cystoid macular edema, retinal detachment, and exacerbation of diabetic retinopathy. Posterior vitreous detachment can be a fore runner of sight threatening retinal detachment, 3 macular lesions like macular hole, epi retinal membrane.

Optical coherence tomography examination is fast, sensitive, reproducible, non-invasive, non-contact, easy to perform and provide 'in vivo histology' of retina, ${ }^{4,5,6,7,8,9,10,11,12}$ and hence retinal lesions like Cystoid macular edema (CME) are detected early. ${ }^{13}$ It is the early detection and appropriate management of such conditions which provide good visual function to the patient.

\section{Materials and Methods}

This is a prospective study comprising of 50 patients who underwent an uncomplicated small incision cataract surgery by a single surgeon in one year. The patients were enrolled from March 2011 and October 2011, and they were followed up for 3 months. The methodology adhered to the tenets of the Declaration of Helsinki for research involving human subjects. Written informed consent was obtained from all participants and the study was approved by the Institute's Ethics Committee. All patients who underwent an uncomplicated small incision cataract surgery with normal posterior segment were included in the study. Exclusion criterions were preexisting posterior segment changes except diabetic retinopathy, myopia $>6 \mathrm{D}$, complicated or traumatic cataract; previous ocular inflammation/ ocular surgery/ laser treatment or intravitreal injections. Those patients who had dense cataract or other media opacities were excluded because of poor optical coherence tomography images. Patients who had complicated cataract surgery were also excluded.

Patients underwent a detailed history taking regarding presenting complaints, ocular disease, trauma, history of systemic disease including diabetes mellitus. Thorough clinical examination including best corrected visual acuity, refraction, slit lamp examination, detailed fundus examination including slit lamp bio microscopy and indirect ophthalmoscopy was done. Systemic evaluation and routine investigations including blood sugar were performed. Patients underwent USG and OCT of both eyes. USG was done using B scan screening techniques; the area of interest was scanned by longitudinal scan, over closed eyelids.OCT examination was done using line scan, radial scan, and macular thickness mapping options; after dilating pupil to circumvent the media opacity whenever indicated.

Details of surgery, including duration and complications were noted. Postoperative complaints, and complications were looked for. The same procedure was repeated at 1 st week, 1 st month, and 3rd month of postoperative period and the findings were assessed.

For comparison of groups, the descriptive statistics like mean and standard deviations were worked out. Chi-square test was used for testing associations. For all the calculations SPSS was used. Sample size was calculated by using the following formula: $4 \mathrm{pq} / \mathrm{d} 2$, where $\mathrm{p}$ is the proportion of PVD, $\mathrm{q}$ is $(100-$ $\mathrm{p}$ ), and $\mathrm{d}$ is the allowable error i.e., up to $20 \%$ of $\mathrm{p}$. The adequate sample size was 32 .

\section{Observations}

The study enrolled 50 patients, of the age group 40 to 84 years, with mean age of 65.50 years and standard deviation was 10.215 . $62 \%$ were females $38 \%$ were males. $18 \%$ patients were diabetic, $82 \%$ were non-diabetic. 
Pre-operatively, visual acuity ranged from $6 / 9$ to $6 / 36 \mathrm{P} ; 42 \%$ had visual acuity of $6 / 24$ or $6 / 24 \mathrm{P}$. Of the 9 diabetics, 1 had mild and another had moderate non-proliferative diabetic retinopathy (NPDR). 46 patients i.e. 92\% had normal USG while 4 i.e. $8 \%$ had incomplete PVD pre-operatively. Central foveal thickness by OCT was in normal range in all patients before surgery - Normal range for Indian eyes being $149.16+/-21.15 \mu \mathrm{m}$. i.e., (128.01 $\mu \mathrm{m}-170.31 \mu \mathrm{m})$

\section{Distribution according to CFT before surgery for among diabetics and non diabetics}

In the case of non diabetic patients pre-operative Central Foveal Thickness value commonly occurred was $145 \mu \mathrm{m}$. However in the case of diabetic patients, it was bimodal; the most repeated occurrence was of both $140 \mu \mathrm{m}$ and $155 \mu \mathrm{m}$. It was also observed that the variation in CFT was more among diabetic patients than non diabetic patients.

Time taken for surgery in all cases was less than 10 minute.

\section{Distribution according to BCVA after surgery}

None of the patients had best corrected visual acuity less than 6/12P at any time after surgery. After 1 week of surgery Best corrected visual acuity was $6 / 6$ or $6 / 6 \mathrm{P}$ in $26 \%, 6 / 9$ or $6 / 9 \mathrm{P}$ in $52 \%, 6 / 12$ or $6 / 12 \mathrm{P}$ in $22 \%$. At 1 month after surgery; Best corrected visual acuity was $6 / 6$ or $6 / 6 \mathrm{P}$ in $50 \%, 6 / 9$ or $6 / 9 \mathrm{P}$ in $48 \%, 6 / 12$ or $6 / 12 \mathrm{P}$ in $8 \%$. At 3 months after surgery; Best corrected visual acuity was $6 / 6$ or $6 / 6 \mathrm{P}$ in $56 \%, 6 / 9$ or $6 / 9 \mathrm{P}$ in $38 \%, 6 / 12$ or $6 / 12 \mathrm{P}$ in $6 \%$.

\section{Distribution according to findings in fundus after surgery}

Fundus examination after surgery revealed dull foveal reflex in $4 \%$ at 1 week, $2 \%$ at 1 month, $6 \%$ at 3 months. Retinal pigment epithelial changes came into view in $6 \%$ after surgery. No significant progression of diabetic retinopathy occurred.

\section{Distribution according to findings in USG after surgery}

There were $6 \%$ cases of complete PVD at 1 week; these were those patients who had incomplete PVD at the outset; $14 \%$ at 1 month, $20 \%$ at 3 months. 1 case of pre operative incomplete PVD did not progress. Incomplete PVD were seen in $22 \%$ at 1 week, $20 \%$ at 1 month, and $14 \%$ at 3 months. Overall incidence of PVD at 3 months after surgery was $34 \%$. 33 patients had no USG detectable abnormality attributable to surgery. Incidence of complete PVD increased from 1 week to 3 months after surgery; while that of incomplete PVD decreased. Overall incidence of PVD increased from 1 week to 3 months after surgery. [Figure 1 and 2]

Distribution according to the occurrence of findings in macula by OCT after surgery: Cystoid macular edema was seen in $2 \%$ at the end of 3 months, none before. Diffuse macular edema was seen in 1 patient (2\%) 1week after surgery, in $4 \%$ at end of 1 month and 3 months. Totally $6 \%$ had macular edema, of which only $2 \%$ had cystoid macular edema.

No other abnormalities were found in macula by OCT.

Presence of macular edema and age of the patients were independent of each other. [Figure 3]

Association of occurrence of macular edema after surgery and DM

\begin{tabular}{|l|c|c|c|c|}
\hline \multirow{2}{*}{$\begin{array}{l}\text { Macular } \\
\text { Edema }\end{array}$} & \multicolumn{2}{|c|}{ Diabetic } & \multicolumn{2}{c|}{ Non diabetic } \\
\cline { 2 - 5 } & Frequency & Percent & Frequency & Percent \\
\hline Present & 2 & 22.2 & 1 & 2.4 \\
\hline Nil & 7 & 77.8 & 40 & 97.6 \\
\hline Total & 9 & 100 & 41 & 100 \\
\hline
\end{tabular}

There was a statistically significant $(\mathrm{p}<0.05)$ association between the presence of macular edema and the diabetic status of the patient. The event of having macular edema was more likely in diabetic patients than non diabetic patients.

Association of BCVA with macular edema:

\begin{tabular}{|c|c|c|c|c|c|c|}
\hline \multirow{2}{*}{$\begin{array}{l}\text { Macular } \\
\text { edema }\end{array}$} & \multicolumn{2}{|c|}{$\begin{array}{c}\text { V/A } 6 / 6 \text { or } \\
6 / 6 \mathrm{P}\end{array}$} & \multicolumn{2}{|c|}{$\begin{array}{c}\text { V/A } 6 / 9 \text { or } \\
6 / 9 \mathrm{P}\end{array}$} & \multicolumn{2}{|c|}{$\begin{array}{c}\text { V/A 6/12 or } \\
6 / 12 \mathrm{P}\end{array}$} \\
\hline & $\begin{array}{c}\text { Freque } \\
\text { ncy }\end{array}$ & $\begin{array}{l}\text { Perc } \\
\text { ent }\end{array}$ & $\begin{array}{c}\text { Freque } \\
\text { ncy }\end{array}$ & $\begin{array}{l}\text { Perc } \\
\text { ent }\end{array}$ & $\begin{array}{c}\text { Freque } \\
\text { ncy }\end{array}$ & $\begin{array}{l}\text { Perc } \\
\text { ent }\end{array}$ \\
\hline Yes & 1 & 3.6 & 0 & 0 & 2 & 66.7 \\
\hline No & 27 & 96.4 & 19 & 100 & 1 & 33.3 \\
\hline Total & 28 & 100 & 19 & 100 & 3 & 100 \\
\hline
\end{tabular}

The $\mathrm{p}$ value $<0.05$ by chi square test indicates a statistically significant correlation between presence of macular edema and reduction in visual acuity. 
No other posterior segment changes were detected by OCT or USG B-Scan after an uncomplicated cataract surgery

\section{Discussion}

This study aims at finding out the occurrence of changes in the posterior segment of the eye within three months after an uncomplicated Small Incision Cataract Surgery.

The central foveal thickness as per Indian studies $(149.16+/-21.15 \mu \mathrm{m})$ were lower than that of western studies $(182 \pm 23 \mu \mathrm{m})$. The normal central foveal thickness as per present study is $147.80+/$ 17.182, which agrees with the other Indian studies.

In this study, the Incidence of posterior vitreous detachment is $34 \%$ after 3 months of follow up. It is lower when compared to other studies where the incidence was $58.6 \%$ at 1 year and $75.88 \%$ at 5 years. This could be because; in our study mean age was lower and myopia was excluded

Incidence of complete PVD increased from 1 week to 3 months after surgery; while that of incomplete PVD decreased. Overall incidence of PVD increased from 1 week to 3 months after surgery.

There is a statistically significant occurrence of PVD in age group above 65 years.

Incidence of Cystoid macular edema is $2 \%, 1$ patient developed CME at 3months.

A statistically significant association between the presence of macular edema and the diabetic status of the patient could be established. According to Steven et al-CME occurred in $32 \%$ of diabetics without retinopathy, and in $81 \%$ of diabetics with retinopathy at the time of cataract surgery. Ray et al, also identified diabetes mellitus as a risk factor.

A statistically significant correlation between presence of macular edema and reduction in visual acuity was seen in this study.

Macular edema and PVD did not coexist in this study; also the presence of complete PVD has protective effect against CME development.

No other posterior segment changes were detected by USG B-scan or OCT in this study.

\section{Limitations}

- Retinal detachment may develop several years after the uncomplicated cataract surgery. Similarly cystoid macular edema may occur several months after surgery. This necessitates a longer follow up period.

- The study did not include conformation of cystoid macular edema by fundus fluorescein angiography.

- Patients with diabetes mellitus were also included in this study, resulting in increased incidence of post operative macular edema.

\section{Conclusions}

Ultrasonography and optical coherence tomography are non-invasive and efficient tools for assessment of posterior segment of the eye. Ultra sound B-scan effectively detects posterior vitreous detachment. Incidence of pseudophakic posterior vitreous detachment increase with age. Optical coherence tomography aids in the early detection, diagnosis and follow up of cystoid macular edema. Diabetes mellitus appears to predispose a patient to postoperative macular edema and cystoid macular edema seems to be an important cause of reduced visual acuity after uncomplicated cataract surgery.

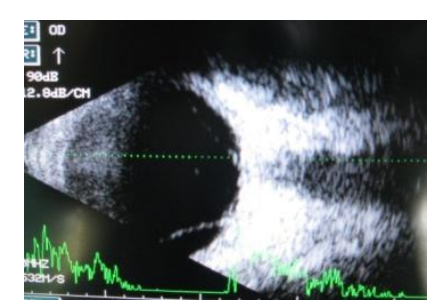

Fig 1: Incomplete PVD

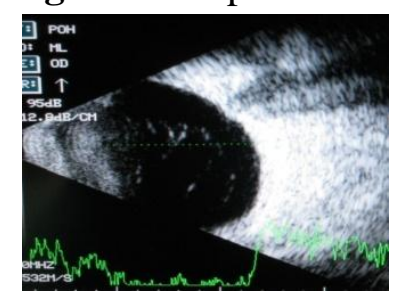

Fig 2: Complete PVD

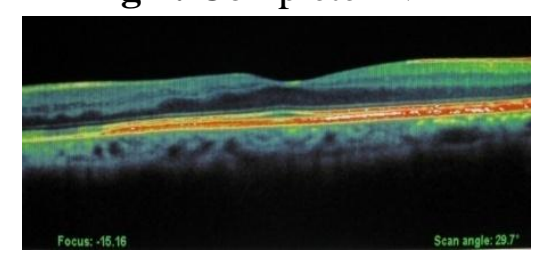

Fig 3: Mild CME 


\section{References}

1. Vision 2020 action plan 2006-2010.WHO

2. Bello TO, AdeotiCO.et al. Ultrasonic assessment in pre-operative cataract patients. Niger Postgrad Med J. 2006 Dec;13(4):3268.

3. Jack J Kanski; Clinical Ophthalmology 6th edition p-698-699.

4. Jaffe GJ, CaprioliJ.et al. Optical coherence tomography to detect and manage retinal disease and glaucoma. Duke Eye Center, Department of Ophthalmology, Duke University Medical Center, Durham, North Carolina 27710, USA.

5. Huang D, Swanson EA, Lin CP, et al. Optical coherence tomography. Science. 1991;254:1178-1181.

6. Figurska M, Robaszkiewicz J, Wierzbowska $\mathrm{J}$ et al. Optical coherence tomography in imaging of macular diseases. Am J Ophthalmol. 2004 Jan;137(1):156-69.

7. Pedut-Kloizman T, Paktera HM, Schuman JS, Szwartz JC, HeeMR.et al. OphthalClin North Am 1998;11:465-87.

8. Massin P, Vicaut E, Haouchine B, Erginay A, Paques M, GaudricA.et al. Reproducibility of retinal mapping using optical coherence tomography. Arch Ophthalmol 2001;119:1135-42.

9. Schuman J, Pedut-Kloizman T, Hertzmark E, Hee MR, Wilkins JR, Coker JG, et al. Reproducibility of nerve fiber layer thickness measurement using optical coherence tomography. Ophthalmology 1996;103:1889-98.

10. Muscat S, Parks S, Kemp E, Keating D.et al. Repeatability and reproducibility of macular thickness measurements with Humphrey OCT system. Invest Ophthalmol Vis Sci 2002;43:490-95.

11. Koozekanani D, Roberts C, Katz SE, HerderickEE.et al. Intersession repeatability of macular thickness measurements with the Humphrey 2000 OCT. Invest Ophthalmol Vis Sci 2000;41:1486-91.
12. Hee MR, Puliafito CA, Wong C, Duker JS, Reichel E, Rutledge B, et al. Quantitative assessment of macular edema with optical coherence tomography. Arch Ophthalmol1995; 113:1019-29.

13. Kozak I, Morrison VL, Clark TM, et al. Discrepancy between fluorescein angiography and optical coherence tomography in detection of macular disease. Retina. 2008;28(4):538-544. 